Journal of Advanced Research in Fluid Mechanics and Thermal Sciences

\title{
Numerical Solutions of Hybrid Nanofluids Flow Via Free Convection Over a Solid Sphere
}

\author{
Mohammed Zaki Swalmeh ${ }^{1, *}$ \\ 1 Faculty of Arts and Sciences, Aqaba University of Technology, Aqaba, Jordan
}

\begin{tabular}{ll}
\hline ARTICLE INFO & ABSTRACT \\
\hline $\begin{array}{l}\text { Article history: } \\
\text { Received } 28 \text { November } 2020\end{array}$ & $\begin{array}{l}\text { The purpose of the existing study is to examine how heat transfer enables consolidated } \\
\text { beceived in revised form } 9 \text { April } 2021\end{array}$ \\
$\begin{array}{l}\text { Accepted } 13 \text { April } 2021 \\
\text { thailable online } 19 \text { May } 2021\end{array}$ & $\begin{array}{l}\text { water as a hybrid nanofluid flow on a solid sphere is also considered in this work. The } \\
\text { partial differential equations are gotten, for this problem, by transforming the } \\
\text { mathematical governing equations using similarity equations (stream function). These } \\
\text { partial differential equations are solved numerically by Keller-Box method and } \\
\text { programmed by MATLAB program. The acquired numerical results are in excellent } \\
\text { agreement with the preceding literature results. Graphical results of the influence of } \\
\text { the hybrid nanofluid parameters on some physical quantities regarded to examine the } \\
\text { behavior of hybrid nanofluid flow were attained, and they proved that hybrid nanofluid } \\
\text { flow represents a more essential role in the operation of heat transfer than a regular } \\
\text { neywords: }\end{array}$ \\
$\begin{array}{l}\text { Hybrid nanofluid; Boundary Layer Flow; } \\
\text { nolid Sphere }\end{array}$
\end{tabular}

\section{Introduction}

At present time, the nano technology is continued to heat transfer enhancement, and it stays a matter of senior attention in the studies and sciences. When nanofluids expression was introduced by Choi and Eastman [1], considerable many searches have been widely achieved related to the charactaristcs of nanofluids on heat transfer and fluid flow. After that, two important kinds of simulations models permanently applied to discuss the demeanors of nanofluid, such as single-phase model and two-phase model, which are conducted by Tiwari and Das [2] and Buongiorno [3], respectively. Swalmeh et al., [4-8] and Alwawi et al., [9-12] used the one phase model to study the convection boundary layer flow in nanofluid over solid sphere and horizontal circular cylinder. And many papers investigated the two phase model like Sheikholeslami et al., [13], Garoosi et al., [14], Rea et al., [15]. Furthermore, many researchers reported distinct articles concerning the in boundary layer flow in a nanofluid. Noor et al., [16] stidied the problem of convection heat transfer on stagnation point in micropolar nanofluid. The convection boundary-layer flow over a horizontal

\footnotetext{
${ }^{*}$ Corresponding author.

E-mail address: msawalmeh@aut.edu.jo
}

https://doi.org/10.37934/arfmts.83.1.3445 
circular cylinder with a porous medium in presence of nanofluid were investigated by Rashad et al., [17]. Hussanan et al., [18] looked in convection heat transfer in micropolar nanofluids with oxide nanoparticles. Also, Hussain et al., [19] studied the analysis of micropolar nanofluid flow past a stretching surface [20-24].

A few years ago, experimental study of nanofluids called "hybrid nanofluids" are considered by Suresh et al., [25]., which is suggested to present better heat trensfer advantages and rheological conduct along with improved thermo-physical features. Hybrid nanofluid is an stretching of nanofluid which collected of two various nanoparticles suspended in the base fluid. Hybrid nanofluids are vastly utilized in numerous fields of enhancement heat transfer, such as electronic cooling, acoustics, coolant in machining, supercomputers, transportation, military, pharmaceutical, biomedical, nuclear safety. Devi and Devi [26] numerically studied the problem of hydro-magnetic hybrid $\mathrm{Cu}-\mathrm{Al}_{2} \mathrm{O}_{3} /$ water nanofluid flow. On stagnation-point flow of an aqueous $\mathrm{TiO}_{2}-\mathrm{Cu}$ hybrid nanofluid on a wavy cylinder was considered by Yousefi et al., [27]. Hayat et al., [28] studied the rotating hybrid flow of Ag$\mathrm{CuO} / \mathrm{H}_{2} \mathrm{O}$ nanofluid under radiation and partial slip boundary effects. Rehman et al., [29] conducted the three-dimensional in existence of micropolar hybrid nanofluid flow past an exponentially stretched surface. And in the survey articles, such as Hussien et al., [30], Tlili et al., [31], Murray [32], Hussain et al., [33], Babu et al., [34], Ahmadi et al., [35], Ali et al., [36].

Depending on the aforementioned above publications for this special hybrid nanofluid flow, the efforts were gone to inspect heat transfer elaboration in free convection flow of iron-graphene oxide suspended in water as a hybrid nanofluid over a solid sphere, with two boundary conditions, namely constant wall temperature (CWT) and constant heat flux (CHF). In the engineering field, the amount of enhancement of composition of nanofluid as hybrid nanofluid brings a lot of wide prospects especially in the development of modern industries. Besides, this study problem can be extended to another studies, like influences of magneto-hydrodynamics, micropolar, or Casson fluid, in presence of convection boundary layer flow with hybrid nanofluid. Hence, the numerical results for physical quantities can be gained for these influences parameters. Moreover, this research is an expansion and stretching of some previous research, check Manjunatha et al., [37], Waini et al., [38], Nadeem et al., [39], and Hamarsheh et al., [40].

\section{Mathematical Formulation}

The problem of steady laminar free convection boundary layer flow in presence of an incompressible hybrid nanofluid, on a solid sphere, is investigated. The $x$-axis measured in the circumference of the solid sphere surface motion from the lower stagnation point $(x \approx 0)$, and the $y$-axis is measured perpendicular to it. Also, the constant wall temperature (CWT) $\left(T_{w}\right)$ and constant heat flux (CHF) $\left(q_{w}\right)$ boundary conditions, are studied in this problem, as shown in Figure 1. $T_{w}$ is the wall temperature, $q_{w}$ is the heat flux constant, $T_{\infty}$ the ambient temperature of the fluid which does not change, $g$ is the gravity vector which affects in the opposite direction.

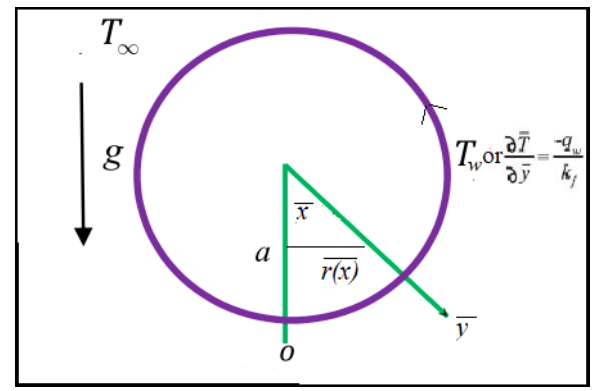

Fig. 1. Schematic physical model 
Subject to the above suppositions, the continuity, momentum, and thermal equations, of the boundary layer flow of the hybrid nanofluids, on a solid sphere, are obtained by Salleh et al., [48], Manjunatha et al., [37]

$\frac{\partial(\bar{r} \bar{u})}{\partial \bar{x}}+\frac{\partial(\bar{r} \bar{v})}{\partial \bar{y}}=0$,

$\rho_{h n f}\left(\bar{u} \frac{\partial \bar{u}}{\partial \bar{x}}+\bar{v} \frac{\partial \bar{u}}{\partial \bar{y}}\right)=\mu_{h n f}\left(\frac{\partial^{2} \bar{u}}{\partial \bar{x}^{2}}\right)-(\beta)_{h n f} \mathrm{~g}\left(T-T_{\infty}\right) \sin \frac{\bar{x}}{a^{\prime}}$

$\bar{u} \frac{\partial T}{\partial \bar{x}}+\bar{v} \frac{\partial T}{\partial \bar{y}}=\alpha_{h n f}\left(\frac{\partial^{2} \bar{T}}{\partial \bar{y}^{2}}\right)$

subject the two boundary conditions defined by Swalmeh et al., [6] and Nazar et al., [41] as

$\bar{u}=0, \bar{v}=0, T=T_{w}(\mathrm{CWT})$ or $\frac{\partial T}{\partial \bar{y}}=\left(-\frac{\bar{q}_{w}}{k_{f}}\right)(\mathrm{CHF})$, as $\bar{y}=0$,

$\bar{u} \rightarrow 0, T \rightarrow T_{\infty}$, as $\bar{y} \rightarrow \infty$.

Here, $(\bar{u}, \bar{v})$-velocity components along $(x, y)$ coordinate respectively, $\bar{r}(\bar{x})$ is the radial distance from the symmetrical axis to the surface of the sphere, $a$ is constant. $\rho_{h n f}, \mu_{h n f}, \mathrm{~g},(\beta)_{h n f},(\alpha)_{h n f}=$ $\frac{k_{h n f}}{\left(\rho c_{p}\right)_{h n f}}$ are the density of hybrid nanofluid, viscosity of hybrid nanofluid, gravity acceleration, coefficient of thermal expansion of hybrid nanofluid, and Thermal diffusivity coefficient of the hybrid nanofluid, respectively. $T, T_{\infty}$ are the temperature of fluid and ambient temperature, $k_{f}$ and $k_{\text {hnf }}$ are the thermal conductivity of based fluid and hybrid nanofluid, $\left(\rho c_{p}\right)_{h n f}$ is the heat capacity of hybrid nanofluid, $\bar{q}_{w}$ is constant heat flux. The thermo-physical properties for used nanoparticles and based fluid are presented in Table 1. Also, the hybrid nanofluid properties are displayed by Table 2.

\section{Table 1}

Different values of thermo-physical properties of nanoparticles of one base fluid [42]

\begin{tabular}{llll}
\hline Physical properties & Water & GO & Fe \\
\hline $\mathrm{k}(\mathrm{W} / \mathrm{mK})$ & 0.613 & 5000 & 9.7 \\
$\rho\left(\mathrm{kg} / \mathrm{m}^{3}\right)$ & 997.1 & 1800 & 5180 \\
$\rho c_{p}(\mathrm{~J} / \mathrm{kgK})$ & 4179 & 717 & 670 \\
$\mathrm{Pr}$ & 6.2 & $\ldots$ & $\ldots$ \\
\hline
\end{tabular}

\section{Table 2}

Thermo-physical model [37]

\begin{tabular}{lll}
\hline & Properties of nanofluid & Properties of hybrid nanofluid \\
\hline 1. & $(\beta)_{n f}=\left(\gamma_{2}(\beta)_{s}+\left(1-\gamma_{2}\right)(\beta)_{f}\right)$, & $(\beta)_{h n f}=\left(1-\gamma_{2}\right)\left[\left(1-\gamma_{1}\right)(\beta)_{f}+\gamma_{1}(\beta)_{s 1}\right]+\gamma_{2}(\beta)_{s 2}$, \\
2. $\quad(\mu)_{n f}=\frac{\mu_{f}}{\left(1-\gamma_{2}\right)^{2.5}}$, & $(\mu)_{h n f}=\frac{\mu_{f}}{\left(1-\gamma_{1}\right)^{2.5}\left(1-\gamma_{2}\right)^{2.5},}$, \\
3. $\quad\left(\rho c_{p}\right)_{n f}=\left(\gamma_{2}\left(\rho c_{p}\right)_{s}+\left(1-\gamma_{2}\right)\left(\rho c_{p}\right)_{f}\right)$, & $\left(\rho c_{p}\right)_{h n f}=\left(1-\gamma_{2}\right)\left[\left(1-\gamma_{1}\right)\left(\rho c_{p}\right)_{f}+\gamma_{1}\left(\rho c_{p}\right)_{s 1}\right]$ \\
4. $\quad(\alpha)_{n f}=\frac{k_{n f}}{\left(\rho c_{p}\right)_{n f}^{\prime}}$, & $(\alpha)_{h n f}=\frac{k_{h n f}}{\left(\rho c_{p}\right)_{h n f}}, \gamma_{2}\left(\rho c_{p}\right)_{s 2}$, \\
5. $\quad \frac{k_{n f}}{k_{f}}=\frac{\left(k_{s}+2 k_{f}\right)-2 \gamma_{2}\left(k_{f}-k_{s}\right)}{\left(k_{s}+2 k_{f}\right)+\gamma_{2}\left(k_{f}-k_{s}\right)}$. & $\frac{k_{h n f}}{k_{b f}}=\frac{\left(k_{s 2}+2 k_{f}\right)-2 \gamma_{2}\left(k_{b f}-k_{s 2}\right)}{\left(k_{s 2}+2 k_{b f}\right)+\gamma_{2}\left(k_{b f}-k_{s 2}\right)^{\prime}}$ \\
& $\frac{k_{b f}}{k_{f}}=\frac{\left(k_{s 1}+2 k_{f}\right)-2 \gamma_{1}\left(k_{f}-k_{s 1}\right)}{\left(k_{s 1}+2 k_{f}\right)+\gamma_{1}\left(k_{f}-k_{s 1}\right)}$. \\
\hline
\end{tabular}


where $\gamma_{2}$ is the volume fraction for the Fe, $\gamma_{1}$ is the volume fraction for GO. $\left(\gamma_{2}=\gamma_{1}=0\right)$ are represent to a regular Newtonian fluid. Besides, to simplify the above problem equations, we get the following non-dimensional variables, as follows $[9,10]$

$$
\begin{aligned}
& r=\left(\frac{\bar{r}}{a}\right), x=\left(\frac{\bar{x}}{a}\right), \\
& \left\{y=(G r)^{(1 / 4)}\left(\frac{\bar{y}}{a}\right), \theta=\frac{T-T_{\infty}}{T_{w^{-}} T_{\infty}}, u=(G r)^{(-1 / 2)}\left(\frac{a \bar{u}}{v_{f}}\right), v=(G r)^{(-1 / 4)}\left(\frac{a \bar{v}}{v_{f}}\right)\right\}(\mathrm{CWT}), \\
& \left\{y=(G r)^{(1 / 5)}\left(\frac{\bar{y}}{a}\right), \theta=(G r)^{(1 / 5)}\left(\frac{T-T_{\infty}}{\frac{a \bar{q}_{w}}{k_{f}}}\right), u=(G r)^{(-2 / 5)}\left(\frac{a \bar{u}}{v_{f}}\right), v=(G r)^{(-1 / 5)}\left(\frac{a \bar{v}}{v_{f}}\right)\right\}(\mathrm{CHF}), \\
& G r=g(\beta)_{f}\left(T_{w}-T_{\infty}\right) a^{3} / v_{f}^{2}(C W T), G r=g(\beta)_{f}\left(\frac{a \bar{q}_{w}}{k_{f}}\right) a^{3} / v_{f}^{2}(\mathrm{CHF}),
\end{aligned}
$$

such that $G r$ is the Grashof number. $v_{f}$ is Kinematic viscosity of the fluid. The above non-dimensional variables along (5) have utilized in Eq. (1) to Eq. (4) to obtain the next non-dimensional equations, subject to two boundary conditions, namely constant wall temperature and constant heat flux.

$u \frac{\partial r u}{\partial x}+v \frac{\partial r u}{\partial y}=0$

$u \frac{\partial u}{\partial x}+v \frac{\partial u}{\partial y}=\frac{\rho_{f}}{\rho_{h n f}}\left(\frac{\mu_{f}}{\left(1-\gamma_{1}\right)^{2.5}\left(1-\gamma_{2}\right)^{2.5}}\right)\left(\frac{\partial^{2} u}{\partial y^{2}}\right)+\frac{1}{\rho_{h n f}}\left(\left(1-\gamma_{2}\right)\left[\left(1-\gamma_{1}\right) \rho_{f}+\gamma_{1} \frac{\rho_{s 1} \beta_{s 1}}{\beta_{f}}\right]+\right.$ $\left.\gamma_{2} \frac{\rho_{s 2} \beta_{s 2}}{\beta_{f}}\right) \theta \sin x$

$u \frac{\partial \theta}{\partial x}+v \frac{\partial \theta}{\partial y}=\frac{1}{\operatorname{Pr}}\left(\frac{k_{h n f} / k_{f}}{\left(1-\gamma_{2}\right)\left[\left(1-\gamma_{1}\right) \rho_{f}+\gamma_{1} \frac{\gamma_{1}\left(\rho c_{p}\right)_{s 1}}{\left(\rho c_{p}\right)_{f}}\right]+\gamma_{2} \frac{\gamma_{2}\left(\rho c_{p}\right)_{s 2}}{\left(\rho c_{p}\right)_{f}}}\right)\left(\frac{\partial^{2} \theta}{\partial \bar{y}^{2}}\right)$

where, $\operatorname{Pr}=\frac{v_{f}}{\alpha_{f}}$ is the Prandtl number.

The boundary conditions (4) become

$$
\begin{aligned}
& u=0, v=0, \theta=1 \text { (CWT)or } \frac{\partial \theta}{\partial y}=-1(\mathrm{CHF}) \text {, as } y=0, \\
& u \rightarrow 0, \theta \rightarrow 0, \text {, as } y \rightarrow \infty .
\end{aligned}
$$

To solve the Eq. (6) to Eq. (8), subject to the boundary conditions (9), we assume the following variables [9]

$\psi=x r(x) f(x, y), \theta=\theta(x, y)$

such that $\psi$ is the stream function defined as

$$
u=\frac{1}{r} \frac{\partial \psi}{\partial y}, \text { and } v=\frac{1}{r} \frac{\partial \psi}{\partial x}
$$


which satisfies the continuity Eq. (6), then the Eq. (6) to Eq. (8) become

$$
\begin{aligned}
& \frac{\rho_{f}}{\rho_{h n f}}\left(\frac{\mu_{f}}{\left(1-\gamma_{1}\right)^{2.5}\left(1-\gamma_{2}\right)^{2.5}}\right) \frac{\partial^{3} f}{\partial x^{3}}+(1+x \cot x) f \frac{\partial^{2} f}{\partial x^{2}}-\left(\frac{\partial f}{\partial y}\right)^{2}+\frac{1}{\rho_{n f}}\left(( 1 - \gamma _ { 2 } ) \left[\left(1-\gamma_{1}\right) \rho_{f}+\right.\right. \\
& \left.\left.\gamma_{1} \frac{\rho_{s 1} \beta_{s 1}}{\beta_{f}}\right]+\gamma_{2} \frac{\rho_{s 2} \beta_{s 2}}{\beta_{f}}\right) \theta \frac{\sin x}{x}=x\left(\frac{\partial f}{\partial y} \frac{\partial^{2} f}{\partial x \partial y}-\frac{\partial f}{\partial x} \frac{\partial^{2} f}{\partial y^{2}}\right) \\
& \frac{1}{\operatorname{Pr}}\left(\frac{k_{h n f} / k_{f}}{\left(1-\gamma_{2}\right)\left[\left(1-\gamma_{1}\right) \rho_{f}+\gamma_{1} \frac{\gamma_{1}\left(\rho c_{p}\right)_{s 1}}{\left(\rho c_{p}\right)_{f}}\right]+\gamma_{2} \frac{\gamma_{2}\left(\rho c_{p}\right)_{s 2}}{\left(\rho c_{p}\right)_{f}}}\right)\left(\frac{\partial^{2} \theta}{\partial y^{2}}\right)+f \frac{\partial \theta}{\partial y}=x\left(\frac{\partial f}{\partial y} \frac{\partial \theta}{\partial x}-\frac{\partial f}{\partial x} \frac{\partial \theta}{\partial y}\right),
\end{aligned}
$$

subject to the boundary conditions

$$
\begin{aligned}
& f=\frac{\partial f}{\partial y}=0, \theta=1(\mathrm{CWT}) \text { or } \frac{\partial \theta}{\partial y}=-1(\mathrm{CHF}) \text {, as } y=0, \\
& \frac{\partial f}{\partial y} \rightarrow 0, \theta \rightarrow 0, \text { as } y \rightarrow \infty .
\end{aligned}
$$

It can be seen that at the lower stagnation point of the sphere, $x \approx 0$, the above equations reduce to the following ordinary differential equations:

$$
\begin{aligned}
& \frac{\rho_{f}}{\rho_{h n f}}\left(\frac{\mu_{f}}{\left(1-\gamma_{1}\right)^{2.5}\left(1-\gamma_{2}\right)^{2.5}}\right) \frac{\partial^{3} f}{\partial x^{3}}+2 \frac{\partial^{2} f}{\partial x^{2}}-\left(\frac{\partial f}{\partial y}\right)^{2}+\frac{1}{\rho_{n f}}\left(\left(1-\gamma_{2}\right)\left[\left(1-\gamma_{1}\right) \rho_{f}+\gamma_{1} \frac{\rho_{s 1} \beta_{s 1}}{\beta_{f}}\right]+\right. \\
& \left.\gamma_{2} \frac{\rho_{s 2} \beta_{s 2}}{\beta_{f}}\right) \theta \frac{\sin x}{x}=0, \\
& \frac{1}{\operatorname{Pr}}\left(\frac{k_{h n f} / k_{f}}{\left(1-\gamma_{2}\right)\left[\left(1-\gamma_{1}\right) \rho_{f}+\gamma_{1} \frac{\gamma_{1}\left(\rho c_{p}\right)_{s 1}}{\left(\rho c_{p}\right)_{f}}\right]+\gamma_{2} \frac{\gamma_{2}\left(\rho c_{p}\right)_{s 2}}{\left(\rho c_{p}\right)_{f}}}\right)\left(\frac{\partial^{2} \theta}{\partial y^{2}}\right)+f \frac{\partial \theta}{\partial y}=0 .
\end{aligned}
$$

The boundary conditions become

$$
\begin{aligned}
& f(0)=f^{\prime}(0)=0, \theta=1(\mathrm{CWT}) \text { or } \theta^{\prime}=-1(\mathrm{CHF}) \text {, as } y=0 \\
& f^{\prime} \rightarrow 0, \theta \rightarrow 0 \text {, as } y \rightarrow \infty
\end{aligned}
$$

where primes denote differentiation with respect to $y$.

The physical quantities of interest in this problem are the local skin friction coefficient $C_{f}$, the Nusselt number $\mathrm{Nu}$ and local wall temperature $\theta_{w}$, and they can be written as

$$
\left(C_{f}=\frac{G r^{-3 / 4} a^{2}}{\mu_{f} v_{f}} \tau_{w}, N u=\frac{a}{k_{f}\left(T_{f}-T_{f}\right)} q_{w}\right)(\mathrm{CWT}),\left(\theta_{w}=\theta(x, 0), C_{f}=\frac{G r^{-2 / 5} a^{2}}{\mu_{f} v_{f}} \tau_{w}\right)(\mathrm{CHF}),
$$

where $\tau_{w}$ is Surface shear stress, and defined as

$$
\tau_{w}=\mu_{h n f}\left(\frac{\partial \bar{u}}{\partial \bar{y}}\right)_{\bar{y}}, q_{w}=-k_{h n f}\left(\frac{\partial T}{\partial \bar{y}}\right)_{\bar{y}=0},
$$


By using the non-dimensional variables (5) and boundary conditions (9) the local skin friction coefficient $C_{f}$ and Nusselt number $\mathrm{Nu}$ become

$C_{f}=G r^{-1 / 4}\left(\frac{\mu_{f}}{\left(1-\gamma_{1}\right)^{2.5}\left(1-\gamma_{2}\right)^{2.5}}\right) x \frac{\partial^{2} f}{\partial y^{2}}(x, 0), G r^{-1 / 4} N u=-G r^{1 / 4} \frac{k_{f}}{k_{n f}}\left(\frac{\partial \theta}{\partial y}\right)(x, 0),(\mathrm{CWT})$

\section{Results and Discussions}

Numerical solutions of the nonlinear partial differential equations, Eq. (12) and Eq. (11), under the two boundary conditions, such that (CWT) and (CHF), Eq. (14), are solved employing the Kellerbox method available in the Matlab software. For a long time, This method well-known solver that has been vastly utilized by many researchers to solve the convection boundary layer flow problems, see Keller [43], Nazar [44], Tham et al., [45], and Hamarsheh, et al., [40]. Thermo-physical properties of used based fluids and nanoparticles in this study are shown in Table 1. The numerical solutions are gained using an initial estimation provided at an initial profile, at the lower stagnation point of the sphere $x=0$, and follow up around the sphere up to $x=100^{\circ}$. In the special case, viscous Newtonian fluid, we get a suitable step size $(x, y)$, and then comparing theses solutions with formerly published numerical results reported by Alwawi et al., [10] and Cheng [46]. We checked that the present results are in good agreement accuracy, as displayed in Table 3 and Table 4.

Table 3

Comparison of local skin friction coefficient $N u$ with Newtonian fluid $\left(\gamma_{1}=\gamma_{2}=0\right)$ at $\operatorname{Pr}=0.7$

\begin{tabular}{llll}
\hline$x^{\circ}$ & Cheng [46] & Alwawi et al., $[10]$ & Present \\
\hline $0^{\circ}$ & 0.4576 & 0.4576 & 0.4576 \\
$10^{\circ}$ & 0.4565 & 0.4565 & 0.4565 \\
$20^{\circ}$ & 0.4534 & 0.4534 & 0.4533 \\
$30^{\circ}$ & 0.4481 & 0.4480 & 0.4480 \\
$40^{\circ}$ & 0.4407 & 0.4406 & 0.4405 \\
$50^{\circ}$ & 0.4310 & 0.4310 & 0.4311 \\
$60^{\circ}$ & 0.4191 & 0.4194 & 0.4192 \\
$70^{\circ}$ & 0.4049 & 0.4053 & 0.4050 \\
$80^{\circ}$ & 0.3881 & 0.3886 & 0.3882 \\
$90^{\circ}$ & 0.3686 & 0.3693 & 0.3685 \\
\hline
\end{tabular}

\section{Table 4}

Comparison of local skin friction coefficient $C_{f}$ with Newtonian fluid $\left(\gamma_{1}=\gamma_{2}=0\right)$ at $\operatorname{Pr}=0.7$

\begin{tabular}{llll}
\hline$x^{\circ}$ & Huang and Chen [47] & Alwawi et al., [9] & Present \\
\hline $0^{\circ}$ & 0.0000 & 0.0000 & 0.0000 \\
$10^{\circ}$ & 0.2138 & 0.2123 & 0.2133 \\
$20^{\circ}$ & 0.4247 & 0.4157 & 0.4250 \\
$30^{\circ}$ & 0.6299 & 0.6252 & 0.6288 \\
$40^{\circ}$ & 0.8265 & 0.8201 & 0.8259 \\
$50^{\circ}$ & 1.0118 & 1.0033 & 1.0105 \\
$60^{\circ}$ & 1.1828 & 1.1676 & 1.1811 \\
$70^{\circ}$ & 1.3376 & 1.3198 & 1.3366 \\
$80^{\circ}$ & 1.4708 & 1.4519 & 1.4713 \\
$90^{\circ}$ & 1.5818 & 1.5609 & 1.5809 \\
\hline
\end{tabular}


In this section, understanding the impact of hybrid nanofluid parameters $\gamma_{1}$ and $\gamma_{2}$ on physical quantities for the problem of free convection boundary layer flow in a hybrid nanofluid is discussed. In this research, the nanoparticle of graphene oxide is added to the base fluid with nanoparticle volume fraction $\gamma_{1}$ equal to 0.1 . Subsequently, Fe is added with a different value of nanoparticle volume fraction $\gamma_{2}$ to compose the hybrid nanofluid namely Fe-GO/water. The hybrid nanofluid parameter $\gamma_{2}$ values are studied from 0.007 to 0.06 . Variations of the skin friction coefficient, local wall temperature, and the local Nusselt number, as well as the velocity and temperature profiles, are offered in plotted form through Figure 2 to Figure 8, with two boundary conditions (CWT) and (CHF). The influences of $\mathrm{Nu}$ and $\theta_{w}$, are demonstrated in Figure 2 and Figure 3. It illustrates that an increase in $\gamma_{2}$ increases $N u$ (CWT) and $\theta_{w}$ (CHF), with an increase in the values in $x$. On the other hand, it is observed that there is a drop in the fluid moment in Nusselt number $\mathrm{Nu}$ along with the momentum angle $x$-direction. But the opposite case happens, there is a raise in the fluid moment in local wall temperature along with the momentum the angle $x$-direction. It is cleared that in the subsistence of a charismatic field, the change in the heat transfer $\mathrm{Nu}$ and $\theta_{w}$ of hybrid nanofluid $\left(\mathrm{Fe}-\mathrm{GO} / \mathrm{H}_{2} \mathrm{O}\right)$ is higher than that of nanofluid $\left(\mathrm{Fe} / \mathrm{H}_{2} \mathrm{O}\right)$. Therefore, we understand that the expected heat transfer rate can be got by a convenient complex of nanoparticle magnitude.

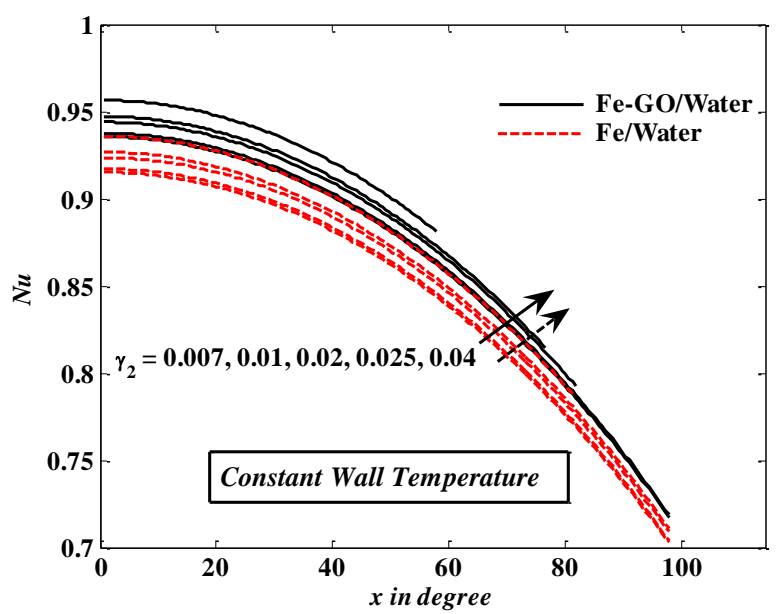

Fig. 2. The influence of $\gamma_{2}$ on $\mathrm{Nu}$

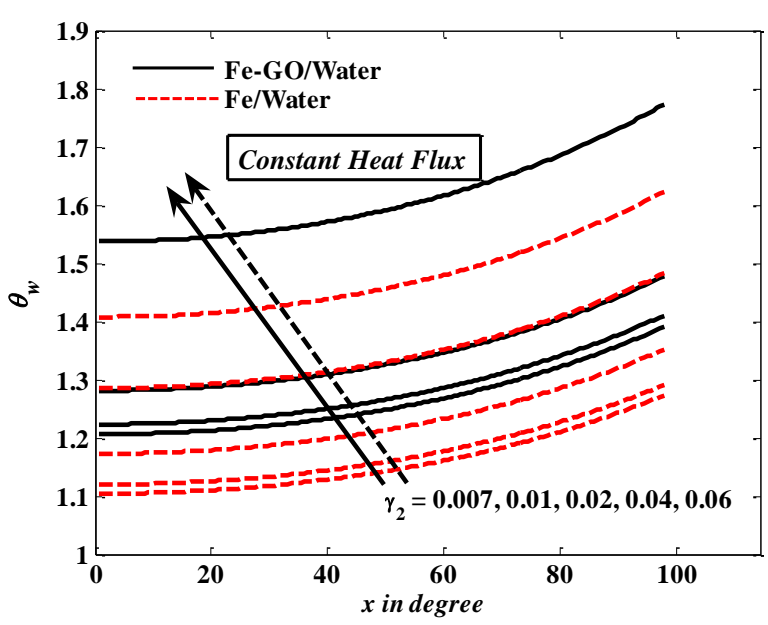

Fig. 3. The influence of $\gamma_{2}$ on $\theta_{w}$

The characteristics of $C_{f}$ are studied in Figure 4 and Figure 5 . These figures signalize that with the increasing values of $\gamma_{2}$, the flow in local skin friction quantity is faster for both the nanofluid and the combination of nanofluids. Besides, the local skin friction values for hybrid nanofluid $\left(\mathrm{Fe}-\mathrm{GO} / \mathrm{H}_{2} \mathrm{O}\right)$ are greater than nanofluid $\left(\mathrm{Fe} / \mathrm{H}_{2} \mathrm{O}\right)$, with two (CWT) and (CHF) boundary conditions. Also, It indicates that when the nanoparticle volume fraction values $\gamma_{2}$ are raising, the $C_{f}$ quantity values are reducing, in presence of the $\left(\mathrm{Fe}-\mathrm{GO} / \mathrm{H}_{2} \mathrm{O}\right)$ and $\left(\mathrm{Fe} / \mathrm{H}_{2} \mathrm{O}\right)$.

Figure 6 to Figure 9 depicted the behaviours of $\gamma_{1}$ and $\gamma_{2}$ on temperature and velocity profiles. It presents that an increase in $\gamma_{2}$ increases the temperature but the velocity decreases, with an associated thickness of the boundary layer increases. Physically, the boost in temperature and decrease in velocity between the surface and the ambient hybrid nanofluid is due to the increase in the concentration of nanoparticle density. It deduces that we get the optimizations in convection currents. In addition, $\mathrm{GO}-\mathrm{Fe} / \mathrm{H}_{2} \mathrm{O}$ has high temperature and velocity profiles compared to $\mathrm{Fe} / \mathrm{Water}$ with an increase in the values of $\gamma_{2}$. 


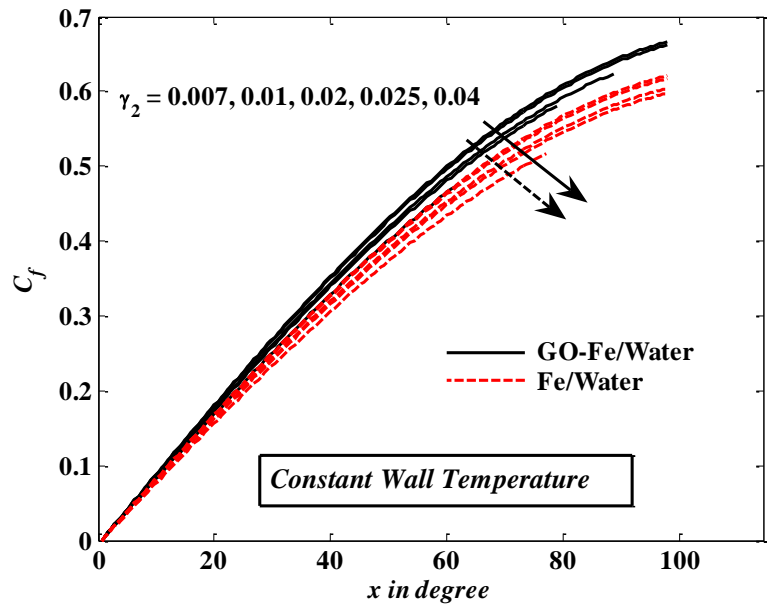

Fig. 4. The influence of $\gamma_{2}$ on $C_{f}$

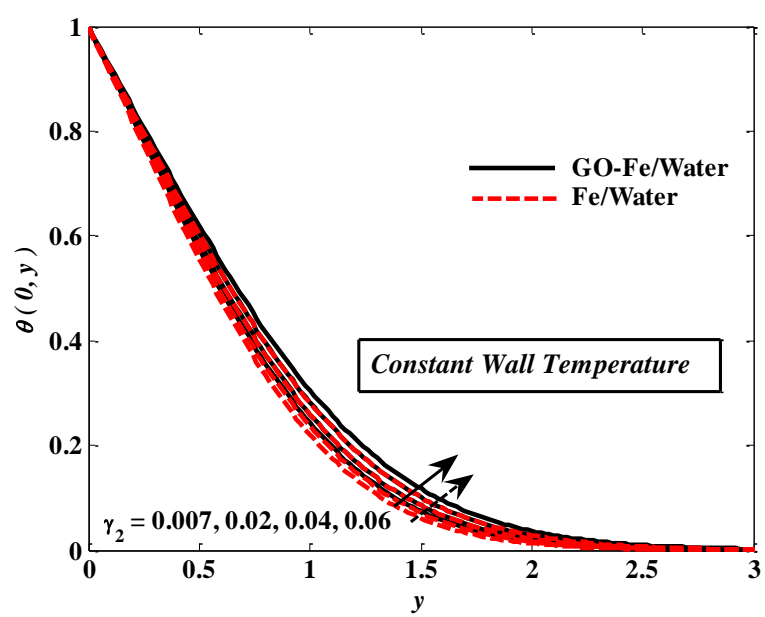

Fig. 6. The influence of $\gamma_{2}$ on $\theta(0, y)$

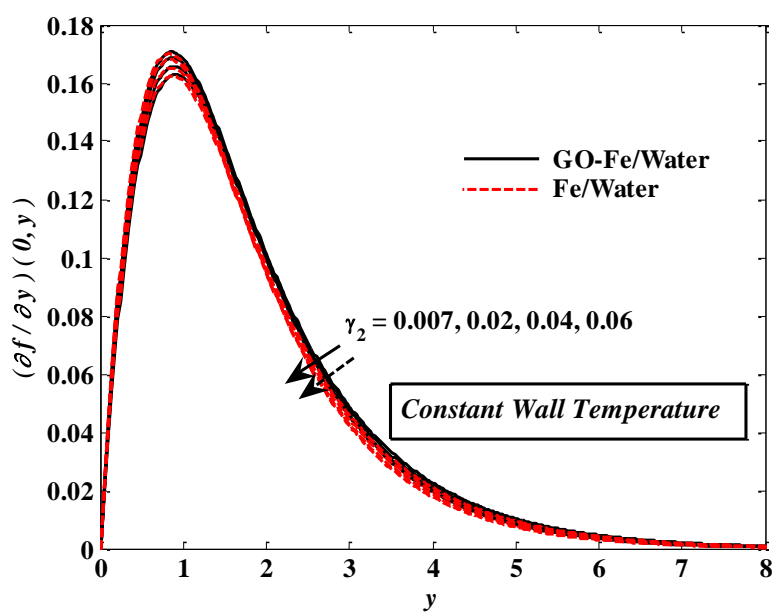

Fig. 8. The influence of $\gamma_{2}$ on $(\partial f / \partial y)(0, y)$

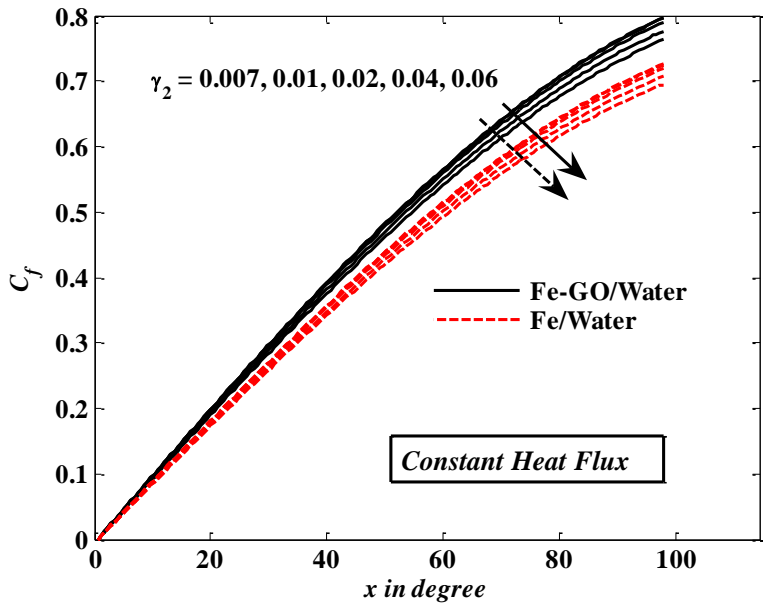

Fig. 5. The influence of $\gamma_{2}$ on $C_{f}$

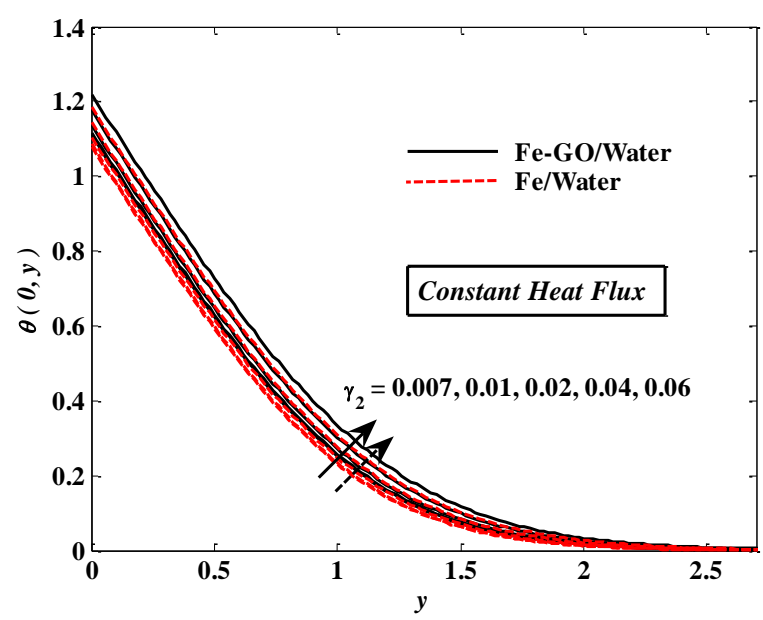

Fig. 7. The influence of $\gamma_{2}$ on $\theta(0, y)$

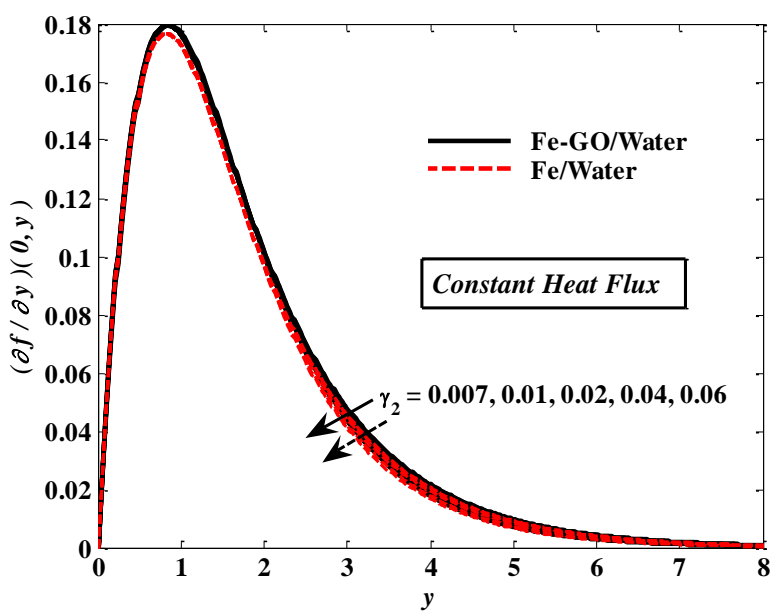

Fig. 9. The influence of $\gamma_{2}$ on $(\partial f / \partial y)(0, y)$ 


\section{Conclusions}

Research on the convection heat transfer boundary layer flow in presence of hybrid nanofluid are considered significant value in engineering sciences. To address the affair, this article presents mathematical model and numerical results for the heat transfer impacts for free convection in hybrid nanofluid flow over a solid sphere. The appropriate similarity transformation is utilized to convert the governing equations into partial differential equations. These partial differential equations are numerically solved by Keller box method and programmed with MATLAB program. The obtained numerical results for the effects of hybrid nanofluid parameters on the engineering interesting physical quantities are investigated in an attempt to discuss them through several figures and tables. Also, (CWT) and (CHF) boundary conditions have been considered in this investigation. The following significant observations are concluded of this study, as follows

i. When the nanoparticle volume fraction parameter $\gamma_{2}$ increases, the values of local Nusselt number, local wall temperature, and temperature profile are increased, of both regular nanofluid and hybrid nanofluid flows

ii. The local skin friction coefficient and the velocity profile are increased by an increment of nanoparticle volume fraction $\gamma_{2}$ of both regular nanofluid and hybrid nanofluids flows.

iii. Fe-GO/water hybrid nanofluid has a higher temperature and velocity profile compared with $\mathrm{Fe} /$ water nanofluid with an increase in the nanofluid parameter $\gamma_{2}$.

iv. Also, Fe/ Weter nanofluid has lower local skin friction, local wall temperature, and local Nusselt number than Fe-GO/ Water hybrid nanofluid, with (CWT) and (CHF) boundary conditions.

v. Hybrid nanofluid flow represents a more essential character in the operation of heat transfer than a regular nanofluid flow.

\section{Acknowledgement}

This research was supported by Aqaba University of Technology.

\section{References}

[1] Choi, S. US, and Jeffrey A. Eastman. Enhancing thermal conductivity of fluids with nanoparticles. No. ANL/MSD/CP84938; CONF-951135-29. Argonne National Lab., IL (United States), 1995.

[2] Tiwari, Raj Kamal, and Manab Kumar Das. "Heat transfer augmentation in a two-sided lid-driven differentially heated square cavity utilizing nanofluids." International Journal of Heat and Mass transfer 50, no. 9-10 (2007): 2002-2018. https://doi.org/10.1016/i.ijheatmasstransfer.2006.09.034

[3] Buongiorno, Jacopo. "Convective transport in nanofluids." Journal of Heat Transfer 128 (2006): $240-250$. https://doi.org/10.1115/1.2150834

[4] Swalmeh, Mohammed Z., Hamzeh T. Alkasasbeh, Abid Hussanan, T. Nguyen Thoi, and Mustafa Mamat. "Microstructure and inertial effects on natural convection micropolar nanofluid flow about a solid sphere." International Journal of Ambient Energy (2019): 1-12. https://doi.org/10.1080/01430750.2019.1665582

[5] Swalmeh, Mohammed Z., Hamzeh T. Alkasasbeh, Abid Hussanan, and Mustafa Mamat. "Numerical investigation of heat transfer enhancement with Ag-GO water and kerosene oil based micropolar nanofluid over a solid sphere." Journal of Advanced Research in Fluid Mechanics and Thermal Sciences 59, no. 2 (2019): 269-282.

[6] Swalmeh, Mohammed Z., Hamzeh T. Alkasasbeh, Abid Hussanan, and Mustafa Mamat. "Heat transfer flow of Cuwater and Al2O3-water micropolar nanofluids about a solid sphere in the presence of natural convection using Keller-box method." Results in Physics 9 (2018): 717-724. https://doi.org/10.1016/j.rinp.2018.03.033

[7] Swalmeh, M. Z., H. T. Alkasasbeh, A. Hussanan, and M. Mamat. "Numerical Study of Mixed Convection Heat Transfer in Methanol based Micropolar Nanofluid about a Horizontal Circular Cylinder." In Journal of Physics: Conference Series, vol. 1366, no. 1, p. 012003. IOP Publishing, 2019. https://doi.org/10.1088/1742$\underline{6596 / 1366 / 1 / 012003}$ 
[8] Swalmeh, Mohammed Z., Hamzeh T. Alkasasbeh, Abid Hussanan, and Mustafa Mamat. "Influence of micro-rotation and micro-inertia on nanofluid flow over a heated horizontal circular cylinder with free convection." Theoretical and Applied Mechanics 46, no. 2 (2019): 125-145. https://doi.org/10.2298/TAM181120008S

[9] Alwawi, Firas A., Hamzeh T. Alkasasbeh, Ahmad M. Rashad, and Ruwaidiah Idris. "Natural convection flow of Sodium Alginate based Casson nanofluid about a solid sphere in the presence of a magnetic field with constant surface heat flux." In Journal of Physics: Conference Series, vol. 1366, no. 1, p. 012005. IOP Publishing, 2019. https://doi.org/10.1088/1742-6596/1366/1/012005

[10] Alwawi, Firas A., Hamzeh T. Alkasasbeh, A. M. Rashad, and Ruwaidiah Idris. "MHD natural convection of Sodium Alginate Casson nanofluid over a solid sphere." Results in Physics 16 (2020): 102818. https://doi.org/10.1016/i.rinp.2019.102818

[11] Alwawi, Firas A., Hamzeh T. Alkasasbeh, A. M. Rashad, and Ruwaidiah Idris. "Heat transfer analysis of ethylene glycol-based Casson nanofluid around a horizontal circular cylinder with MHD effect." Proceedings of the Institution of Mechanical Engineers, Part C: Journal of Mechanical Engineering Science 234, no. 13 (2020): 2569-2580. https://doi.org/10.1177/0954406220908624

[12] Alwawi, Firas A., Hamzeh T. Alkasasbeh, Ahmed M. Rashad, and Ruwaidiah Idris. "A numerical approach for the heat transfer flow of carboxymethyl cellulose-water based Casson nanofluid from a solid sphere generated by mixed convection under the influence of Lorentz force." Mathematics 8, no. 7 (2020): 1094. https://doi.org/10.3390/math8071094

[13] Sheikholeslami, M., D. D. Ganji, and M. M. Rashidi. "Magnetic field effect on unsteady nanofluid flow and heat transfer using Buongiorno model." Journal of Magnetism and Magnetic Materials 416 (2016): 164-173. https://doi.org/10.1016/i.jmmm.2016.05.026

[14] Garoosi, Faroogh, Leila Jahanshaloo, Mohammad Mehdi Rashidi, Arash Badakhsh, and Mohammed E. Ali. "Numerical simulation of natural convection of the nanofluid in heat exchangers using a Buongiorno model." Applied Mathematics and Computation 254 (2015): 183-203. https://doi.org/10.1016/i.amc.2014.12.116

[15] Rea, Ulzie, Tom McKrell, Lin-wen Hu, and Jacopo Buongiorno. "Laminar convective heat transfer and viscous pressure loss of alumina-water and zirconia-water nanofluids." International Journal of Heat and Mass Transfer 52, no. 7-8 (2009): 2042-2048. https://doi.org/10.1016/i.ijheatmasstransfer.2008.10.025

[16] Noor, N. F. M., Rizwan Ul Haq, S. Nadeem, and I. Hashim. "Mixed convection stagnation flow of a micropolar nanofluid along a vertically stretching surface with slip effects." Meccanica 50, no. 8 (2015): $2007-2022$. https://doi.org/10.1007/s11012-015-0145-9

[17] Rashad, A. M., A. J. Chamkha, and M. Modather. "Mixed convection boundary-layer flow past a horizontal circular cylinder embedded in a porous medium filled with a nanofluid under convective boundary condition." Computers \& Fluids 86 (2013): 380-388. https://doi.org/10.1016/j.compfluid.2013.07.030

[18] Hussanan, Abid, Mohd Zuki Salleh, Ilyas Khan, and Sharidan Shafie. "Convection heat transfer in micropolar nanofluids with oxide nanoparticles in water, kerosene and engine oil." Journal of Molecular Liquids 229 (2017): 482-488. https://doi.org/10.1016/j.molliq.2016.12.040

[19] Hussain, S. T., Sohail Nadeem, and Rizwan UI Haq. "Model-based analysis of micropolar nanofluid flow over a stretching surface." The European Physical Journal Plus 129, no. 8 (2014): 1-10. https://doi.org/10.1140/epjp/i2014-14161-8

[20] Qadan, Hani, Hamzeh Alkasasbeh, Nusayba Yaseen, Mohammed Z. Sawalmeh, and Shaima ALKhalafat. "A Theoretical study of steady MHD mixed convection heat transfer flow for a horizontal circular cylinder embedded in a micropolar casson fluid with thermal radiation." Journal of Computational Applied Mechanics 50, no. 1 (2019): 165-173.

[21] Alzgool, Husein A., Hamzeh T. Alkasasbeh, Sana Abu-ghurra, Zain Al-houri, and Mohammed Z. Swalmeh. "Numerical solution of heat transfer in MHD mixed convection flow micropolar Casson fluid about solid sphere with radiation effect." International Journal of Engineering Research and Technology 12, no. 4 (2019): 519-529.

[22] Abro, Kashif Ali, Ilyas Khan, and J. F. Gomez-Aguilar. "Heat transfer in magnetohydrodynamic free convection flow of generalized ferrofluid with magnetite nanoparticles." Journal of Thermal Analysis and Calorimetry (2020): 1-10. https://doi.org/10.1007/s10973-019-08992-1

[23] Aly, Emad H., and I. Pop. "MHD flow and heat transfer near stagnation point over a stretching/shrinking surface with partial slip and viscous dissipation: hybrid nanofluid versus nanofluid." Powder Technology 367 (2020): 192205. https://doi.org/10.1016/i.powtec.2020.03.030

[24] Abbas, Nadeem, S. Nadeem, and M. Y. Malik. "Theoretical study of micropolar hybrid nanofluid over Riga channel with slip conditions." Physica A: Statistical Mechanics and Its Applications 551 (2020): 124083. https://doi.org/10.1016/i.physa.2019.124083 
[25] Suresh, S., K. P. Venkitaraj, P. Selvakumar, and M. Chandrasekar. "Synthesis of Al2O3-Cu/water hybrid nanofluids using two step method and its thermo physical properties." Colloids and Surfaces A: Physicochemical and Engineering Aspects 388, no. 1-3 (2011): 41-48. https://doi.org/10.1016/j.colsurfa.2011.08.005

[26] Devi, SP Anjali, and S. Suriya Uma Devi. "Numerical investigation of hydromagnetic hybrid Cu-Al2O3/water nanofluid flow over a permeable stretching sheet with suction." International Journal of Nonlinear Sciences and Numerical Simulation 17, no. 5 (2016): 249-257. https://doi.org/10.1515/ijnsns-2016-0037

[27] Yousefi, Mohammad, Saeed Dinarvand, Mohammad Eftekhari Yazdi, and loan Pop. "Stagnation-point flow of an aqueous titania-copper hybrid nanofluid toward a wavy cylinder." International Journal of Numerical Methods for Heat \& Fluid Flow (2018). https://doi.org/10.1108/HFF-01-2018-0009

[28] Hayat, Tanzila, S. Nadeem, and A. U. Khan. "Rotating flow of Ag-CuO/H 2 O hybrid nanofluid with radiation and partial slip boundary effects." The European Physical Journal E 41, no. 6 (2018): 1-9. https://doi.org/10.1140/epje/i2018-11682-y

[29] Rehman, Fiaz Ur, Sohail Nadeem, Hafeez Ur Rehman, and Rizwan UI Haq. "Thermophysical analysis for threedimensional MHD stagnation-point flow of nano-material influenced by an exponential stretching surface." Results in Physics 8 (2018): 316-323. https://doi.org/10.1016/j.rinp.2017.12.026

[30] Hussien, Ahmed A., Wael Al-Kouz, Nadiahnor Md Yusop, Mohd Z. Abdullah, and Ayub Ahmed Janvekar. "A Brief Survey of Preparation and Heat Transfer Enhancement of Hybrid Nanofluids." Strojniski Vestnik/Journal of Mechanical Engineering 65 (2019). https://doi.org/10.5545/sv-jme.2019.6077

[31] Tlili, Iskander, M. M. Bhatti, Samir Mustafa Hamad, Azeez A. Barzinjy, M. Sheikholeslami, and Ahmad Shafee. "Macroscopic modeling for convection of Hybrid nanofluid with magnetic effects." Physica A: Statistical Mechanics and Its Applications 534 (2019): 122136. https://doi.org/10.1016/i.physa.2019.122136

[32] Murray, Fiona. "The oncomouse that roared: Hybrid exchange strategies as a source of distinction at the boundary of overlapping institutions." American Journal of Sociology 116, no. 2 (2010): 341-388. https://doi.org/10.1086/653599

[33] Hussain, S., Sameh E. Ahmed, and T. Akbar. "Entropy generation analysis in MHD mixed convection of hybrid nanofluid in an open cavity with a horizontal channel containing an adiabatic obstacle." International Journal of Heat and Mass Transfer 114 (2017): 1054-1066. https://doi.org/10.1016/j.ijheatmasstransfer.2017.06.135

[34] Babu, JA Ranga, K. Kiran Kumar, and S. Srinivasa Rao. "State-of-art review on hybrid nanofluids." Renewable and Sustainable Energy Reviews 77 (2017): 551-565. https://doi.org/10.1016/j.rser.2017.04.040

[35] Ahmadi, Mohammad Hossein, Amin Mirlohi, Mohammad Alhuyi Nazari, and Roghayeh Ghasempour. "A review of thermal conductivity of various nanofluids." Journal of Molecular Liquids 265 (2018): 181-188. https://doi.org/10.1016/i.molliq.2018.05.124

[36] Ali, Naser, Joao A. Teixeira, and Abdulmajid Addali. "A review on nanofluids: fabrication, stability, and thermophysical properties." Journal of Nanomaterials 2018 (2018). https://doi.org/10.1155/2018/6978130

[37] Manjunatha, S., B. Ammani Kuttan, S. Jayanthi, Ali Chamkha, and B. J. Gireesha. "Heat transfer enhancement in the boundary layer flow of hybrid nanofluids due to variable viscosity and natural convection." Heliyon 5, no. 4 (2019): e01469. https://doi.org/10.1016/i.heliyon.2019.e01469

[38] Waini, Iskandar, Anuar Ishak, and Ioan Pop. "Hybrid nanofluid flow and heat transfer over a nonlinear permeable stretching/shrinking surface." International Journal of Numerical Methods for Heat \& Fluid Flow (2019). https://doi.org/10.1088/1742-6596/1366/1/012022

[39] Nadeem, S., Nadeem Abbas, and A. U. Khan. "Characteristics of three dimensional stagnation point flow of hybrid nanofluid past a circular cylinder." Results in Physics 8 (2018): 829-835. https://doi.org/10.1016/i.rinp.2018.01.024

[40] Hamarsheh, Abdulkareem Saleh, Firas A. Alwawi, Hamzeh T. Alkasasbeh, Ahmed M. Rashad, and Ruwaidiah Idris. "Heat Transfer Improvement in MHD Natural Convection Flow of Graphite Oxide/Carbon Nanotubes-Methanol Based Casson Nanofluids Past a Horizontal Circular Cylinder." Processes 8, no. 11 (2020): 1444. https://doi.org/10.3390/pr8111444

[41] Nazar, R., N. Amin, T. Groşan, and I. Pop. "Free convection boundary layer on a sphere with constant surface heat flux in a micropolar fluid." International Communications in Heat and Mass Transfer 29, no. 8 (2002): 1129-1138. https://doi.org/10.1016/S0735-1933(02)00441-4

[42] Mutuku-Njane, Winifred Nduku. "Analysis of hydromagnetic boundary layer flow and heat transfer of nanofluids." PhD diss., Cape Peninsula University of Technology, 2014.

[43] Keller, Herbert B. "A new difference scheme for parabolic problems." In Numerical Solution of Partial Differential Equations-II, pp. 327-350. Academic Press, 1971. https://doi.org/10.1016/B978-0-12-358502-8.50014-1

[44] Nazar, Roslinda Mohd. "Mathematical models for free and mixed convection boundary layer flows of micropolar fluids." PhD diss., Universiti Teknologi Malaysia, 2004. 
[45] Tham, Leony, Roslinda Nazar, and loan Pop. "Numerical solutions of mixed convection boundary layer flow near the lower stagnation point of a horizontal circular cylinder in a nanofluid." Far East Journal of Mathematical Sciences 73 (2013): 97-118.

[46] Cheng, Ching-Yang. "Natural convection heat and mass transfer from a sphere in micropolar fluids with constant wall temperature and concentration." International Communications in Heat and Mass Transfer 35, no. 6 (2008): 750-755. https://doi.org/10.1016/i.icheatmasstransfer.2008.02.004

[47] Huang, Mingjer, and Gahokuang Chen. "Laminar free convection from a sphere with blowing and suction." Journal of Heat Transfer (Transactions of the ASME (American Society of Mechanical Engineers), Series C);(United States) 109, no. 2 (1987).

[48] Salleh, M. Z., R. Nazar, and I. Pop. "Modeling of free convection boundary layer flow on a solid sphere with Newtonian heating." Acta Applicandae Mathematicae 112, no. 3 (2010): 263-274. https://doi.org/10.1007/s10440$\underline{010-9567-5}$ 